\title{
A visão de jornalistas brasileiros sobre o potencial de influência dos editoriais políticos no debate público atual
}

\section{The view of Brazilian journalists on the potential influence of political editorials in the current public debate}

\author{
Antônio Teixeira de Barros* \\ *Professor, Centro de Formação e Treinamento da Câmara dos Deputados (CEFOR)
}

Resumo:

\begin{abstract}
O editorial jornalístico já exerceu grande influência no debate político. Entretanto, com as transformações tecnológicas e as mudanças culturais recentes, ainda é possível afirmar que esse gênero é influente politicamente na atualidade? Essa é a principal questão discutida no texto. Para tanto, foram entrevistados 120 jornalistas brasileiros que atuam na área política, a fim de captar suas percepções. A pesquisa foi realizada em março de 2017. As principais conclusões mostram que os jornalistas que atuam na área política são leitores de editoriais sobre o tema com regularidade e consideram que este gênero jornalístico ainda é relativamente influente no campo político e no debate público de modo geral, embora seja expressiva a parcela que considera que tal influência é cada vez menor. A diversidade de canais de opinião na atualidade, especialmente com as mídias digitais, e o declínio da mídia impressa são apontadas como as principais razões para a crescente perda da influência dos editoriais na arena política e na opinião pública.
\end{abstract}

Palavras-chave: Jornalismo político; Debates públicos; Editorial jornalístico; Esfera pública; Jornalismo e política.

Abstract:

The journalistic editorial has already exerted great influence in the political debate. However, with technological changes and recent cultural changes, is it still possible to affirm that this genre is politically influential today? This is the main issue discussed in the text. For that, 120 Brazilian journalists were interviewed who work in the political area, in order to capture their perceptions. The research was conducted in March 2017. The main conclusions show that journalists who work in the political field are regular readers of the subject and consider that this journalistic genre is still relatively influential in the political field and in public debate in general, Although the portion that considers such influence is decreasing is significant. The diversity of opinion channels today, especially with digital media, and the decline of print media are singled out as the main reasons for the growing loss of editorial influence in the political arena and in public opinion.

Keywords: Political journalism; Public debates; Editorial journalistic; Public sphere; Journalism and politics.

\section{Introdução}

Há estudos sociológicos que ressaltam a importância política do jornalismo, em função do caráter institucional dessa atividade e do potencial dos jornalistas para atuarem como estratos condutores, ou seja, como atores sociais capazes de transportar ideias ou valores para a sociedade, como já argumentava Max Weber em 1910, ao propor um programa de pesquisa sobre sociologia da imprensa (Weber, 2005 [1910]; 1999). Weber ressaltava o fato específico de que a imprensa tem o poder de tornar públicos certos temas, questões e agendas, com a particularidade de envolver variados atores políticos, como os partidos, as grandes empresas e "os inumeráveis grupos e pessoas que influem na vida pública e são influenciados por 
ela" (Weber, 2005 [1910], p.15). De forma similar Cook (1998) argumenta que a imprensa exerce uma atuação política de natureza tipicamente institucional, pois além de influir na vida social, econômica, política e cultural, também interfere no ato de governar. Isso porque a imprensa se tornou indispensável à democracia no contexto contemporâneo, em uma conjuntura em que os públicos teriam dificuldade de funcionar sem a coparticipação dos atores do campo midiático.

Além de informar, o jornalismo tem a função de promover o debate público de forma pluralista e apartidária, permitindo a livre expressão das várias tendências de pensamento da sociedade. Essa função é exercida pelo chamado jornalismo opinativo, entendido como um gênero que resultou da especialização profissional, conforme explica Wahl-Jorgensen (2008). Apesar das ressalvas à difícil separação entre informação e opinião, cujas fronteiras são ambíguas e nem sempre facilmente demarcáveis (Chaparro, 1994), o fato é que a taxionomia se estabeleceu na literatura e na prática profissional (Beltrão, 1980; Marques de Melo, 1985), com destaque para o editorial, espaço em que "a opinião aparece bem mais explícita do que na notícia do dia a dia" (Guerreiro Neto, 2016, p. 94). Beltrão argumenta que a opinião "valoriza e engrandece a atividade do jornalista", pois quando expressa com honestidade e dignidade, "com a reta intenção de orientar o leitor, sem tergiversar ou violentar a sacralidade das ocorrências, se torna fator importante na opção da comunidade pelo mais seguro caminho à obtenção do bem-estar e da harmonia social" (Beltrão, 1980, p.14).

Mesmo se tratando de uma opinião privada, visto que o editorial expressa a opinião do editor e dos proprietários do jornal ou dos veículos digitais, os editorialistas dialogam preferencialmente com as autoridades públicas, pois tratam de assuntos da agenda pública, especialmente de temas políticos. Nesse sentido, cabe lembrar o argumento de Robert Park (2008) de que o editorial jornalístico é destinado a público-alvo diferenciado, formado por leitores mais intelectualizados, autoridades públicas e dirigentes de instituições que transacionam com o Estado. Firmstone (2008) argumenta ainda que os editoriais expressam a percepção dos jornais sobre o suposto interesse político-ideológico de seus leitores, além de levarem em conta a postura de outros veículos, seus concorrentes.

Por se tratar de um gênero opinativo, o editorial aborda temas controversos e também gera polêmicas. Controvérsias ocorrem nas dinâmicas alimentadas pelo debate público, o qual pressupõe pluralismo, ou seja, a pluralização de universos divergentes de discurso (Habermas, 1999; 2002). As múltiplas visões sobre uma mesma questão discutida na esfera pública devem-se se pautar, segundo a abordagem habermasiana, pela racionalidade comunicativa, ou seja, as controvérsias devem ser tratadas sem coerção moral, em um ambiente comunicativo capaz de instituir um consenso racionalmente construído. Isso implica um clima de debate no qual os participantes superam suas concepções inicialmente subjetivas e parciais em favor de um acordo racionalmente motivado (Habermas, 2002).

Em suma, nessa perspectiva, quanto mais livres e seguros os editorialistas e os jornais/veículos se sentirem, no que se refere à exposição de seus argumentos, mais as controvérsias prosperam, levando ao que Bauman (2010, p.177) denomina de "exacerbação das controvérsias" ou "a pluralidade histórica das verdades". Afinal, complementa: "em um mundo pluralista, não há nenhum sistema inconteste de definição da realidade" (p.178). Por outro lado, o autor alerta para o risco de o pluralismo se transformar em absolutismo múltiplo, ou seja, quando as controvérsias são regidas por lógicas autoritárias de argumentação e construção de consensos. 
Para que efetivamente haja pluralismo, segundo Bauman (2010, p.178) não basta a coexistência de visões diferentes e um relativo clima de liberdade de opinião. O pluralismo, em sua visão, deve ir além disso e permitir a salutar coexistência de "posições comparáveis e rivais que não se podem conciliar". Afinal, pluralismo "é o reconhecimento de que diferentes pessoas e diferentes grupos vivem, literalmente, em mundos diferentes".

Cada vez mais a esfera pública assume papel relevante nas dinâmicas de visibilidade e discutibilidade das denúncias e causas públicas, inserindo os diversos atores na construção argumentativa em torno das questões suscitadas pela repercussão das controvérsias. Isso favorece a formação de diversos tipos de comunidades discursivas e comunidades de interesse, que passam a mobilizar diferentes modalidades de recursos críticos em seus modos de apresentar suas críticas e justificações, nas diferentes cadeias de mediação proporcionadas pela atuação cada vez mais ramificada das mídias digitais, que permitem a circulação de variados pontos de vista.

A propósito, Guerreiro Neto (2016, p.92) argumenta que, apesar da crise dos jornais impressos e da popularidade da Internet, os editoriais migram para o ambiente online e ocupam ainda um lugar significativo no cenário midiático, considerando o modelo tradicional e as novas formas de jornalismo opinativo na Web. "Não mantêm, no entanto, a mesma força de influência sobre a opinião pública, na medida em que há uma rede de discursos que se imbricam e interagem no ambiente digital, para além de um sujeito institucionaldiscursivo agregador como o jornal impresso".

Convém ressaltar que o editorial jornalístico já exerceu grande influência no debate político e na construção e resolução de controvérsias políticas. Entretanto, com as transformações tecnológicas e as mudanças culturais recentes, ainda é possível afirmar que esse gênero é influente politicamente na atualidade? Essa é a principal questão discutida no texto, com o objetivo de proporcionar uma avaliação crítica sob a perspectiva dos próprios jornalistas. 0 detalhamento das estratégias metodológicas será feito antes da análise das entrevistas. Na seção a seguir tratamos da relação entre editoriais jornalísticos, política e seu potencial de influência no debate público.

\section{Editoriais jornalísticos, política e debate público}

O editorial jornalístico constitui um discurso, em forma de texto argumentativo, que expressa a opinião do órgão editor acerca de questões relacionadas aos acontecimentos considerados mais importantes, que o jornal noticia ou noticiou recentemente (Barros, 2013). Diferentemente dos textos informativos, o editorial constrói uma interpretação ou um julgamento, com o objetivo de "explicitar o sentido subjacente ao que é apenas noticiado" (Krieger, 1990, p. 159).

O objeto mais comum da interpretação ou julgamento editorial são os fatos ligados às esferas política, administrativa e econômica do país. Assim, os editoriais "cumprem a função comunicativa de fazer saber e de fazer compreender ao público leitor os jogos de conduta dos governantes, as implicações, para a vida do país, das atitudes e decisões governamentais" (Krieger, 1990, p. 159). Com isso, os editoriais expressam seu ponto de vista (privado), sua abordagem (particular) sobre a condução da vida pública (Barros, 2013). 
Essa concepção de editorial jornalístico remete a algumas ideias da teoria liberal da livre imprensa, formulada pelos primeiros pensadores liberais, como Jeremy Benthan, James Mill e John Stuart Mill, entre outros. Segundo essa teoria, a imprensa é concebida como "um fiscal crítico e independente com respeito ao Estado" (Thompson, 1995, p. 323). A expressão livre da opinião, por meio da imprensa - e pela própria - como o meio mais importante para a manifestação de uma diversidade de opiniões é condição indispensável para a formação de uma opinião pública esclarecida, sem a intervenção e abuso de poder por parte do Estado e governos tirânicos e corruptos. Uma imprensa livre e independente funcionaria como uma salvaguarda vital contra o uso despótico do poder político. Assim, a imprensa desempenharia ainda o papel de um vigilante crítico e atento (Barros, 2013). Além de enriquecer o debate político e a esfera do conhecimento, o jornalismo "exporia e criticaria as atividades daqueles que governam e os princípios nos quais baseiam suas decisões" (Thompson, 1995, p. 324).

Conforme Barros (2013, p.67),

"editoriais são entendidos como produtos jornalísticos que resultam da mediação de opiniões privadas. Só que essas opiniões são apresentadas pelos jornais como manifestação de ideias de domínio público, uma vez que resultam da interpretação e julgamento de fatos e acontecimentos que são publicamente mediados, não só pelos próprios jornais que emitem essas opiniões, mas por outros veículos de comunicação".

Diante do exposto, é oportuno discutir o sentido de mediação de opiniões privadas que o editorial assume no contexto atual, conforme mencionado na citação acima, especialmente no caso das mídias digitais, que ampliam a circulação da opinião jornalística. Há três aspectos que gostaríamos de salientar. O primeiro diz respeito ao maior alcance do editorial enquanto opinião privada (de uma empresa jornalística). O segundo refere-se à adesão em maior escala de leitores que podem aceitar tal opinião como sendo expressiva do ponto de vista do domínio público. O terceiro compreende as arenas de refutação que se formam como reações contrárias às opiniões manifestas pelos editoriais. Esses três aspectos considerados conjuntamente aumentam o potencial de influência dos editoriais nas controvérsias públicas nos dias atuais.

Segundo a análise de Dowling (2016), os editoriais jornalísticos, especialmente os que tratavam de política consolidaram-se como gênero jornalístico a partir do século XIX quando se emanciparam da imprensa partidária e passaram a representar um prolongamento da liberdade de expressão, tendo como protagonistas os proprietários dos jornais de opinião. A inserção dos editoriais no contexto da imprensa comercial significou uma mudança expressiva:

"O editorial passou a contribuir para o aumento do público leitor (ou pelo menos buscou evitar a perda a audiência), buscando atrair outros leitores que não partilhavam necessariamente da opinião do dono do jornal. Na era da mídia de massa - incluindo situações de monopólio do espaço público - o editorial será marcado pela tensão entre duas grandes orientações: defender uma opinião sectária e atingir potencialmente a todos. No tempo dos oligopólios, ele passou 
a autoneutralizar o seu poder retórico de fomentar controvérsias, de forma a não se indispor com ninguém. Atualmente, em um movimento pendular, o aumento da mídia segmentada e a preocupação identitária não poderiam libertar o editorial dessa obrigação de agradar a todos e conduzi-lo novamente à afirmação de uma marca e de uma opinião bem delimitada?" (Demers, 2016, p.90).

O editorial é analisado na perspectiva funcionalista da mídia ${ }^{1}$ (Barros, 2015), como mecanismo de interpretação dos eventos noticiados. Essa interpretação ajudaria a esclarecer o público interessado no tema, além de (re)afirmar o próprio status positivo dos emissores perante a sociedade, conquistando legitimidade social e prestígio político. Guerreiro Neto $(2016$, p.92) chama atenção para a função do editorial no que se refere à afirmação da identidade dos jornais, ou seja, "a identidade forjada a partir dessa produção opinativa". Para o autor,

"A discussão sobre a identidade dos jornais costuma seguir por caminhos que levam à forma, ao conteúdo ou à interação entre ambos. Ou seja, a partir da materialidade do periódico, emergem as marcas de identificação. A proposta aqui é, sem desconsiderar o jornal como produto, investigar esses traços indicadores da identidade nos processos de produção. O processo produtivo do jornalismo, enquanto práticas institucionais e discursivas organizadas, atua como um terceiro elemento gerador e reprodutor de identidade" (Guerreiro Neto, 2016, p.92).

É cabível aqui um questionamento sobre a relação entre o editorial e a identidade dos jornais e dos demais veículos midiáticos, posto que nem sempre tais veículos assumem uma postura política definida e duradoura na atualidade. Cada vez mais é comum que a opinião expressa nos editoriais seja motivada por interesses políticos momentâneos e flexíveis, sem necessidade de um compromisso opinativo de longo prazo, como ocorria no passado, quando era possível identificar claramente - a partir da leitura dos editoriais políticos o perfil dos jornais como sendo de direita, centro ou esquerda. No atual contexto, acreditamos que seja cada vez mais difícil deduzir a identidade dos veículos com base nos editoriais.

Segundo a avaliação de Demers (2016, p.88), "o editorial - uma prática quase exclusiva à imprensa escrita - perdeu muito do seu glamour nas últimas décadas". O autor apresenta as principais razões para o declínio da relevância dos editoriais jornalísticos no debate político. A primeira estaria relacionada "à decadência da mídia tradicional, sobretudo os jornais, com a reorganização do panorama midiático e do debate público após a introdução das mídias digitais" (p.88). A segunda se deve ao declínio do poder de palavra dos jornais no cenário contemporâneo, especialmente "como um indicativo da incapacidade dessas organizações de

\footnotetext{
${ }^{1}$ Segundo a perspectiva funcionalista, os mídias exercem quatros funções básicas que se articulam nos seguintes feixes de atividades de regulação e controle social: a vigilância do ambiente social, a interpretação dos eventos noticiados, a transmissão cultural de valores com vistas ao reforço de normas sociais e o entretenimento como função de alívio das tensões sociais do cotidiano (Barros, 2015).
} 
assumirem um posicionamento discursivo ou opinativo no contexto atual" (p.88). Por fim, destaca-se uma nova característica que os jornais assumiram na atualidade, ou seja, seu foco principal é a informação e não mais a opinião, em função da concorrência com os demais veículos informativos.

Para Miguel e Coutinho (2007) os editoriais sobre política revelam a opinião de uma parcela influente da elite, que tende a atuar como "controladores" da imprensa. Azevedo e Chaia (2008, p.180) lembram que o gênero editorial está associado à própria noção de uma imprensa livre, "que vigia o poder e defende o cidadão e, por extensão, a democracia". Foi tal perspectiva que "inspirou a analogia da imprensa como o 'Quarto Poder', expressão cunhada na Inglaterra no século XIX". Para os autores,

"a ideia da imprensa como um atento 'cão de guarda' (e às vezes, motivado pelo jornalismo investigativo, como um verdadeiro 'cão de ataque') se materializa por excelência nas páginas de opinião dos jornais, onde os artigos e as colunas assinadas debatem os temas mais candentes do momento e o editorial define a posição do jornal diante das questões públicas. Deste modo, as páginas opinativas constituem fontes importantes para se apreender e analisar o interesse temático e as formas de enquadramento adotadas pelos jornais em suas abordagens sobre o funcionamento das instituições políticas. O jornalismo opinativo pressupõe expressar a opinião dos meios de comunicação. Este gênero significa que o discurso editorial é baseado em comentários, avaliações e opiniões sobre determinada temática" (Azevedo e Chaia, 2008, p.181).

Ao discorrer sobre o jornalismo opinativo, Campo (2009, p.130) afirma que "o jornalismo não tem apenas o dever de informar e divertir - mesmo quando educa. Também tem o direito e o dever de opinar". Para o autor, "é com a opinião segura, abalizada, bem fundamentada, que o veículo de comunicação cumpre seu papel social a serviço do receptor, agindo com transparência, passando seriedade e credibilidade". O autor ressalva que todo gênero jornalístico pode ser opinativo, pois "a opinião, no sentido ideológico, perpassa, na verdade, todo o processo jornalístico" (Campo, 2001, sem paginação). Para ilustrar seu argumento, o analista exemplifica que era opinativo (e denotava protesto) o espaço em que o Estadão publicava receitas de bolo ou versos dos Lusíadas em substituição a textos proibidos pela censura durante a ditadura militar. $\mathrm{O}$ autor complementa que

"opina-se, então, nos editoriais, nas colunas, nas crônicas, nos artigos, nas cartas dos leitores e, também, no modo de apresentar a matéria, no corte de uma foto, no destaque escolhido para cada parte da matéria, afinal, emitemse opiniões de mil e uma maneiras" (sem paginação).

Erbolato (2002) considera positiva essa característica opinativa da imprensa. Ele explica que, mesmo sendo um discurso institucional o editorial pode contribuir para o esclarecimento do leitor, pois constitui uma espécie de "notícia interpretativa". No entanto, Luiz Amaral (1997) adverte que o editorial deve evitar o estilo panfletário, além de evitar injúrias, ofensas e agressões. Brito (1994) salienta que não se trata de 
apenas discutir se o jornalismo é opinativo ou não. Para a autora, a finalidade do editorial é dirigir a opinião pública, persuadindo através de exortação, apelo, aviso, palavra de ordem ou constatação dos fatos. Segundo sua visão, o editorial moderno não é apenas opinião. A tendência atual é cada vez mais incluir análise, comentário, crítica e clarificação. Por essa razão, o editorial não apenas opina pura e simplesmente, mas também expõe, interpreta, esclarece, analisa padrões e significados da complexa mistura de acontecimentos diários.

Na avaliação de Pedro Celso Campo (01/05/2002), "Os editoriais podem, legitimamente, esclarecer, ilustrar opiniões, induzir a ações e até entreter. $O$ editorial é institucional. É o pensamento oficial do jornal (...) 0 público ao qual se dirige é o definidor do estilo do editorial, mas não do seu conteúdo. Acredita-se que apenas $5 \%$ do universo de leitores de um jornal leiam o editorial do dia. É um público pequeno, mas exigente".

Baccaro e Nascimento (2007, sem paginação) ressaltam que o editorial "é um dos textos jornalísticos mais intrincados, pois é através dele que o jornal se coloca à frente dos fatos que noticia. Isso se dá, no entanto, de maneira sutil, para que se possa passar a impressão de equilíbrio e solidez". Segundo Faria (1996), o editorial é ancorado em ideias, que se expressam por meio de argumentos e crítica, com o intuito claro de demarcar a posição política do jornal sobre o tema editorializado. Para o autor, "a ausência de um autor no editorial se justificaria como maneira de manipular o leitor, fazendo-o acreditar nas 'verdades' do jornal, já que representaria uma visão neutra e equilibrada dos fatos" (sem paginação). Assim, nos editoriais, os veículos atuam como intérpretes da história atual, ao mesmo tempo que tentam ocultar seu papel enquanto parte interessada nessa mesma história (Silva, 2009). Para Lemos e Barros (2016, p.722),

"No espaço discursivo de um jornal, o editorial cumpre ainda a função de demarcador temático da relevância política, social, econômica ou cultural de um fato, uma vez que se trata de um texto argumentativo, com a chancela opinativa do veículo, cuja função é expressar perante os leitores e anunciantes a opinião do órgão editor sobre os temas em exame".

Quanto ao papel de intérpretes da história do tempo presente, apontado acima, consideramos necessário enfatizar a relação dos editoriais tradicionais publicados pelos jornais impressos e sua circulação comentada no ambiente midiático digital. Isso ocorre especialmente nas redes sociais, em que outros atores interpretam os editoriais, aumentando seu poder de inserção social, com o alcance de novos segmentos de públicos. Entre esses novos atores opinantes temos além de jornalistas, intelectuais, políticos, especialistas e leitores leigos, interessados nos temas discutidos. Forma-se, assim, uma esfera alargada de opinião política, em que a objetividade da notícia se associa à análise típica do editorial. A nosso ver, isso torna o editorial nos dias atuais menos um elemento delimitador do gênero opinativo em relação ao gênero informativo e mais um articulador entre os dois gêneros mencionados. 


\section{Emergência e consolidação dos editoriais na imprensa}

Os editoriais são reconhecidos na literatura como herança do jornalismo literário, um gênero tipicamente opinativo identificado por Habermas (1984) como elemento fundador da imprensa na fase literária da esfera pública burguesa, cuja origem está nas cartas-jornais. Essas cartas eram escritas pelos integrantes da alta burguesia europeia e trocadas entre si para compartilhar ideias e opiniões sobre literatura, artes e ciências, algo similar às redes sociais online da atualidade, salvaguardadas as devidas proporções. $O$ avanço do comércio, atividade econômica própria dos burgueses, tornou as cartas-jornais um empreendimento comercial, com vistas à venda de informações de interesse de comerciantes de outras regiões. Esse processo constitui o berço da imprensa. "É expansão da economia de mercado, ainda em sua forma mercantil, que condiciona o aparecimento do jornal nos centros urbanos mais desenvolvidos da época, como Antuérpia, Praga, Estrasburgo e outros" (Barros, 1993, p.267).

A sua própria manifestação inicial, as cartas-jornais, extensão do sistema de correspondência privada da alta burguesia, demonstra que essa "imprensa" surge como elemento interno de uma classe e apresenta uma finalidade específica: servir de suporte ao capitalismo comercial e financeiro produzido a partir da atuação econômica dessa mesma classe. Com a expansão das atividades econômicas, a difusão de informações torna-se uma necessidade do comércio local e ultramarino. "O cálculo capitalista necessita de um fluxo de informações controláveis, regulares e, em geral, acessíveis" (Geyhrofer, 1984, p.63).

As cartas-jornais, como registra Habermas (1984) exerceram uma relevante função na formação da esfera pública burguesa, a qual evoluiria com a publicação dos folhetins nos jornais que começaram a surgir, com grande aceitação do público. É o período do jornalismo literário e sua correspondente fase da esfera pública burguesa literária. Mas a burguesia exige cada vez mais competência crítica dos produtores culturais, para que eles se tornem multiplicadores dos ideais da classe. A imprensa, então, deixa de ser simples transmissora de notícias e se torna condutora da "opinião pública" burguesa. Para Habermas, 1984, p.142,

\footnotetext{
"A verdadeira transformação ocorreu, em verdade, somente com a autonomização da redação, ela iniciou-se com os 'jornais eruditos' no continente, as revistas semanais moralistas e as políticas na Inglaterra, logo que escritores, individualmente, utilizam-se do novo instrumento da imprensa periódica para obter seus argumentos, movidos com intenções pedagógicas e efeitos propagandísticos".
}

Esta é a transição da imprensa literária para a imprensa de opinião, segundo a periodização habermasiana. Como a produção jornalística da época se impõe como empreendimento de baixo custo, dado o seu caráter artesanal, os burgueses ilustrados passam a utilizá-la como meio difusor de suas opiniões. 0 contexto cultural da época favorecia esse tipo de iniciativa, uma vez que a leitura constituía a principal forma de passatempo burguês. As reuniões nos cafés e salões serviam de eco e ressonância para os conteúdos dessas leituras, por meio de debates acalorados. A imprensa de opinião constitui, portanto, a gênese da esfera pública burguesa, definida por Habermas como a esfera das pessoas privadas reunidas em um público. 
A esfera pública burguesa literária consiste em ampliar a autoconscientização da burguesia enquanto classe, promovendo ampla reflexão sobre sua vida social, a partir da esfera íntima da família. A leitura de textos opinativos, de caráter literário, de romances de cunho psicológico constitui uma introdução a esse processo de emancipação psicológica. A esfera pública burguesa literária não possui ainda conotação política. Como afirma Habermas (1984, p.84), ela é o campo de manobras de um raciocínio público que ainda gira em torno de si mesma - "um processo de autocompreensão das pessoas privadas em relação às genuínas experiências de sua nova privacidade".

O amadurecimento dessa experiência resultaria da segunda da fase da esfera pública denominada por Habermas de esfera pública burguesa política, que tem como finalidade afirmar a criticidade do público, problematizando a legitimidade do Estado, o uso público da razão, a regulamentação da sociedade, a defesa das instituições públicas etc. Seu desdobramento é o jornalismo político-literário, que contribui para o exercício da opinião política nos debates públicos da época, questionando as formas de poder e a autoridade absolutista

Essas forças, segundo Habermas, reivindicavam uma esfera pública regulamentada pela autoridade, "mas diretamente contra a própria autoridade", a fim de discutir com ela as leis gerais da troca na esfera pública fundamentalmente privada, mas publicamente relevante, as leis do intercâmbio de mercadorias e do trabalho social (Habermas, 1984, p.42).

Com a consolidação jurídica do Estado de Direito Burguês e o desenvolvimento da sociedade industrial, a imprensa evolui para a fase denominada pelo autor de imprensa de negócios, ou seja, a imprensa comercial, que passa a conceber a notícia como mercadoria e a opinião como uma forma de capital simbólico para atuar no mercado das trocas simbólicas, nos termos de Bourdieu (1989). O editorial jornalístico, nesse contexto, passa a exercer a função de mediação política entre as elites civis e as elites políticas. Para legitimar-se perante a opinião pública, nessa fase da imprensa de negócio, os jornais passaram a investir em informações com a conotação de serviços públicos (Chauí, 1986).

Como foi abordado antes, em tese, o efeito do editorial seria fomentar o debate público, sem impor uma visão unilateral. Entretanto, cabe questionar como se dá esse potencial de influência na atualidade. Nessa etapa do estudo, o propósito é questionar diretamente os atores mais próximos da atividade editorial, ou seja, os próprios jornalistas, conforme será detalhado a seguir. ${ }^{2}$

\section{Estratégias metodológicas}

Para a consecução dos objetivos propostos, foram realizadas 120 entrevistas com profissionais que atuam na área política, nas cinco regiões geográficas do País, a fim de captar suas percepções sobre o papel do editorial político no contexto atual e seu potencial de influência no debate público.

Optamos pelo tipo de entrevista diretiva, com perguntas fechadas e abertas, cujo roteiro foi formatado com o recurso do Google Forms. Também conhecida como entrevista estruturada, centrada ou focada (focused interview), esse instrumento de coleta de dados caracteriza-se pelo seu caráter direcionado, ou seja, voltado

\footnotetext{
${ }^{2}$ Faz parte do escopo da pesquisa estudar a percepção de outros segmentos como os políticos, os intelectuais e os leitores.
} 
para questões específicas. Tais questões constam em um roteiro estruturado, com uma sequência lógica, as quais exigem respostas focadas e mais objetivas dos entrevistados, sem perder o caráter de análise e interpretação que é próprio da entrevista como técnica de pesquisa qualitativa (Quivy e Campenhoudt, 2005).

Foram realizadas as seguintes perguntas: (1) Você lê editoriais sobre política? (2) Explique porque você lê ou não lê editoriais sobre política. (3) Na sua opinião, quais são as principais funções dos editoriais sobre política na atualidade? (4) Como você avalia o potencial de influência dos editoriais sobre política no debate público na atualidade? Após cada questão deixou-se um espaço livre para comentários e opiniões dos informantes, a fim de permitir a captação de subsídios argumentativos para reforçar a análise qualitativa.

Após a formatação do roteiro de entrevista e o pré-teste, o link do roteiro foi enviado por e-mail e divulgado por meio das redes sociais, como Facebook e Twitter, as redes digitais mais utilizadas pelos jornalistas brasileiros na atualidade (Cavalcanti; Rocha Neto, 2014). Esse tipo de recurso é cada vez mais utilizado, devido à facilidade de alcance das pessoas a serem inquiridas. Tal procedimento já é reconhecido na literatura como um instrumento importante para o acesso a pessoas distantes, como no caso da pesquisa em questão, com o mesmo potencial de respostas que o antigo modelo de contato feito por telefone ou carta para acesso aos entrevistados (Manfreda; Vehovar, 2008).

O pré-teste foi realizado com 15 sujeitos, um mês antes da coleta de dados definitiva, cujas respostas foram descartadas. Uma das vantagens dos pré-teste foi aumentar a oferta de espaços para a livre expressão dos entrevistados, pois no primeiro roteiro de entrevista havia sido planejado uma única questão aberta, ao final. Os sujeitos do pré-teste, entretanto, mostraram-se motivados a comentar todas as questões.

Para acesso direto aos jornalistas que atuam na área de política, em jornais impressos e mídias digitais, contamos com a colaboração das seguintes entidades: Associação Brasileira de Jornalismo Político (Abrajorp), Associação Brasileira de Jornalismo Investigativo (Abraji), Federação Nacional dos Jornalistas (Fenaj), Sindicato dos Jornalistas do Distrito Federal e o Comitê de Imprensa do Congresso Nacional. A colaboração dessas entidades foi no fornecimento do mailing de seus associados ou no encaminhamento da carta de apresentação dos pesquisadores com o link para o roteiro de entrevista. Solicitamos também a permissão para a divulgação do referido link no perfil dessas entidades nas redes sociais digitais. Na carta, enfatizava-se que o primeiro requisito para participar da pesquisa era atuar na cobertura sobre política. Como se trata de um público que usa internet diariamente, como ferramenta profissional, acreditamos que a pesquisa não pode ser considerada seletiva ou excludente, visto que os jornalistas brasileiros acessam a web diariamente, como instrumento de trabalho.

Além do uso de recursos da estatística descritiva para agrupar as repostas, a análise qualitativa das entrevistas contou com o auxílio da análise de conteúdo, que consiste na categorização dos temas a partir de seus significados manifestos (Bardin, 2010), o que, no caso das entrevistas, resultou na categorização dos argumentos por afinidade de sentido. Isso implica a sistematização de enunciados de diferentes entrevistados sobre um mesmo assunto, a partir do enfeixamento semântico das respostas, entendendo os depoimentos como expressão de um pensamento coletivo, ou seja, o ponto de vista de uma categoria profissional - no caso os jornalistas. Esse recurso é endossada por Lefèvre e Lefèvre (2003), para os quais essa a técnica é de grande valia para o exame e a compreensão do pensamento das coletividades, com o propósito de mapear, descrever e interpretar a opinião de certos grupos e categorias sociais ou profissionais. 


\section{Análise de dados}

A análise dos dados tem início com a descrição do perfil dos entrevistados, a fim de termos uma noção das características sociodemográficas dos jornalistas que participaram da pesquisa. Em relação ao sexo, há uma relativa paridade, com um leve predomínio de mulheres $(52,5 \%)$. Em relação à faixa etária predominam os entrevistados entre 31 e 60 anos. A maioria trabalha no setor privado (54,2\%), especialmente em mídias digitais $(29,4 \%)$ e impressos (28,6\%). O registro "outros" $(24,1 \%)$ refere-se a jornalistas que atuam em assessorias de imprensa, marketing político, gestão de imagem e reputação política, etc. O tempo de profissão mais expressivo está na faixa de 11 a 20 anos. Acerca da região geográfica, há mais entrevistados das regiões Sudeste e Centro-Oeste, como mostra a Tabela 1. No primeiro caso, justifica-se pela grande quantidade de profissionais que residem no eixo São Paulo-Rio de Janeiro e no segundo caso, cabe lembrar a alta concentração de jornalistas que trabalham na área política em Brasília.

Para os objetivos da pesquisa consideramos o grupo de respondentes adequado, tanto pela abrangência geográfica, como pela diversidade em termos de faixa etária, tempo de profissão, setor de atuação e área de exercício do jornalismo.

Tabela 1: Perfil dos entrevistados

\begin{tabular}{l|l|l}
\hline SEXO & N & $\%$ \\
\hline Feminino & 63 & 52,5 \\
\hline Masculino & 57 & 47,5 \\
\hline Subtotal & 120 & 100 \\
\hline FAIXA ETÁRIA & & \\
\hline Até 30 anos & 10 & 8,3 \\
\hline 31 a 40 anos & 29 & 24,2 \\
\hline 41 a 50 anos & 37 & 30,8 \\
\hline 51 a 60 anos & 25 & 20,8 \\
\hline Acima de 60 & 19 & 15,8 \\
\hline Subtotal & 120 & 100 \\
\hline SETOR DE ATUAÇÃO & & \\
\hline Privado & 65 & 54,2 \\
\hline Público & 35 & 29,2 \\
\hline Terceiro setor & 20 & 16,7 \\
\hline Subtotal & 120 & 100 \\
\hline ÁREA DE ATUAÇÃO & & \\
\hline Mídias digitais & 35 & 29,4 \\
\hline Mídia impressa & 34 & 28,6 \\
\hline Outros & 29 & 24,1 \\
\hline Rádio & 11 & 11,8 \\
\hline & & \\
\hline
\end{tabular}




\begin{tabular}{l|c|c} 
TV & 11 & 11,8 \\
\hline Subtotal & 120 & 100 \\
\hline TEMPO DE PROFISSÃO & & \\
\hline Até 5 anos & 9 & 7,5 \\
\hline 6 a 10 anos & 13 & 10,8 \\
\hline 11 a 15 anos & 29 & 24,2 \\
\hline 16 a 20 anos & 23 & 19,2 \\
\hline Acima de 20 anos & 46 & 38,3 \\
\hline Subtotal & 120 & 100 \\
\hline REGIÃO & & \\
\hline Norte & 10 & 8,3 \\
\hline Nordeste & 18 & 15 \\
\hline Centro-Oeste & 38 & 31,7 \\
\hline Sudeste & 41 & 34,2 \\
\hline Sul & 13 & 10,8 \\
\hline Subtotal & 120 & 100 \\
\hline
\end{tabular}

Fonte: Elaboração própria.

\section{Leitura de editoriais pelos entrevistados}

A leitura de editoriais sobre política é bastante expressiva entre os entrevistados. Como se vê na Tabela 2 apenas um respondeu que não tem o hábito de ler, justificando da seguinte forma: "não leio porque, em geral, os editoriais não acrescentam nada de bom ao que você já sabe; apenas ecoam visões e interesses dos grupos sociais mais privilegiados - é muito senso comum disfarçado de retórica argumentativa". 0 percentual dos que responderam que leem com frequência é de $60,8 \%$, os que leem às vezes é de $18,3 \%$, enquanto os entrevistados que leem com grande frequência é de 15,8 e os aqueles que lêem raramente é de 4,2\% (Tabela 2).

Tabela 2: Você lê editoriais sobre política?

\begin{tabular}{l|c|c}
\hline RESPOSTAS & $\mathbf{N}$ & $\mathbf{\%}$ \\
\hline Leio com frequência & 73 & 60,8 \\
\hline Leio às vezes & 22 & 18,3 \\
\hline Leio com grande frequência & 19 & 15,8 \\
\hline Leio raramente & 5 & 4,2 \\
\hline Não leio & 1 & 0,8 \\
\hline Total & 120 & 100 \\
\hline
\end{tabular}

Fonte: Elaboração própria. 
Os argumentos que justificam as opções de leitura frequente e muito frequente são variados, conforme agrupados na Tabela 3, com predominância do acompanhamento das tendências de opinião, hábito de leitura, interesse pessoal e atualização política.

Tabela 3: Argumentos para justificar a leitura frequente de editoriais

\begin{tabular}{c|c|c}
\hline ARGUMENTOS & $\mathbf{N}$ & $\mathbf{\%}$ \\
\hline Acompanhamento das tendências de opinião & 26 & 28,26 \\
\hline Hábito de leitura & 21 & 22,83 \\
\hline Interesse pessoal & 18 & 19,57 \\
\hline Necessidade de trabalho & 16 & 17,39 \\
\hline Atualização política & 7 & 7,61 \\
\hline Gosto pela política & 4 & 4,35 \\
\hline Total & 92 & 100 \\
\hline
\end{tabular}

Fonte: Elaboração própria.

O acompanhamento das tendências de opinião é justificado por diferentes argumentos. Um dos entrevistados escreveu que,

\footnotetext{
"Tenho interesse em reconhecer o posicionamento político dos jornais, pois tendemos a achar que seja algo já definido, mas como empresas que são os jornais são dinâmicos e, embora tenham posições políticas aparentemente definidas, há nuances que mudam com o tempo e a situação política e econômica, de acordo com os interesses circunstanciais e as tendências do jogo de poder".
}

Outro entrevistado ressalta que "engana-se quem pensa que editorial é mesmice", ao argumentar que "só aqueles que não acompanham os editoriais de jornais é que acham que esse gênero textual não se renova, não evolui". Na opinião desse informante, um aspecto relevante é que "os editoriais acabam trazendo questões que nem sempre são exploradas na cobertura noticiosa e isso é um diferencial, inclusive sob o aspecto político". Seguindo seu raciocínio o jornalista complementa que "se acompanharmos o desenrolar de uma pauta política pela perspectiva dos editoriais, podemos perceber até mudanças de posição dos próprios jornais quanto ao assunto, às vezes em um período mais extenso de tempo, mas isso também pode ocorrer em intervalos mais curtos".

Outro motivo para a leitura de editoriais segundo esse viés de acompanhamento de tendências de opinião diz respeito à produção de discursos sobre política:

"O editorial é uma forma de discurso político que envolve diferentes atores, como as empresas jornalísticas, os editorialistas, os agentes econômicos, os próprios políticos e os leitores interessados na opinião dos jornais. Portanto, eu tenho grande interesse em acompanhar essas tendências discursivas, pois os 
editoriais são muito ricos em termos de estratégias retóricas, formas de argumentação e principalmente como os jornais tentam interpelar os leitores e os que tomam as decisões políticas. É um tipo de discurso que é dirigido a vários segmentos da política, cada um com seu olhar".

Quanto ao hábito de leitura, os argumentos são poucos, resumindo-se a atribuir a leitura ao hábito adquirido ao longo da profissão. Apesar disso, o hábito ainda está arraigado em um expressivo segmento dos entrevistados, com 22,83\%. "Não consigo abrir um jornal e passar batido pelo editorial, pois sempre tenho curiosidade, devido ao longo tempo em que me acostumei a ler jornal dessa maneira". Outro entrevistado avalia como "um bom hábito que adquiri e faço questão de manter, pois me permite acompanhar a cobertura e ver como os jornais estão pensando a política".

Apesar de se tratar de justificativas que não trazem elementos expressivos em termos de aprofundamento analítico, são relevantes no que se refere à cultura profissional, visto que um hábito é sustentado por uma concepção valorativa. Afinal, os valores são considerados ativos simbólicos que operam como guias para orientar tanto os comportamentos individuais como os coletivos, interferindo diretamente nas atitudes (Cantril e Allport, 1993).

O interesse pessoal também é parte dessa cultura profissional, o que se depreende de declarações como a seguinte:

\footnotetext{
"Tenho grande interesse pessoal nos editoriais. Por leio sempre que posso. 0 meu interesse se deve a um pouco de curiosidade para observar a postura dos jornais em relação a determinados assuntos e também em função de quem os editorialistas escolhem como interlocutores preferenciais, ou seja, pelo tom do texto, é possível perceber se os jornais se dirigem aos empresários, aos governantes, aos parlamentares, aos magistrados, etc".
}

A leitura dos editoriais por necessidade profissional é justificada como um "importante instrumento para termos acesso a interpretações e análises sobre o mundo da política, saindo do campo do noticiário". Para o mesmo entrevistado, "como repórter da área política eu sinto muita necessidade de informação, mas isso não é suficiente, pois quando estamos inteirados também sobre o campo da opinião, temos mais elementos para nosso trabalho diário". Outro entrevistado justificou da seguinte forma: "no local onde eu trabalho recebemos muitas pessoas e autoridades, como por exemplo, prefeitos, vereadores, deputados estaduais, etc. e assuntos políticos sempre entram em pauta. Muitas vezes os editoriais são temas dessas conversas". A leitura motivada pela necessidade de atualização política e pelo gosto pela política são justificadas praticamente pelas motivações associadas ao interesse e às razões profissionais.

As razões profissionais enquadram-se no campo denominado por Bourdieu de razões práticas (Bourdieu, 1996), conceito que faz parte de uma teoria da ação focada nas dinâmicas cotidianas e nos mecanismos das práticas rotineiras dos agentes sociais, como no caso dos jornalistas. Tais práticas ocorrem no espaço relacional, entendido pelo autor como "um conjunto de posições distintas e coexistentes", marcadas por "relações de proximidade, vizinhança ou de distanciamento e, também, por relações de ordem, como acima, abaixo e entre" (p. 18). As razões práticas são consideradas por Bourdieu como de grande relevância para 
a compreensão de argumentos acionados pelos agentes sociais quando se referem à sua atividade profissional, por exemplo, como no caso em estudo.

Os entrevistados que afirmaram ler editoriais às vezes ou raramente apresentam como argumentos principais o interesse circunstancial $(44,44 \%)$, a saturação temática $(25,93 \%)$, a preferência pelo noticiário $(14,81 \%)$, a monotonia argumentativa e a falta de tempo, com 7,41\% respectivamente, como se lê na Tabela 4. Da mesma forma que no caso anterior, são argumentos que também se enquadram na perspectiva das razões práticas.

Tabela 4: Argumentos para justificar a falta de leitura frequente de editoriais

\begin{tabular}{l|r|r}
\hline ARGUMENTOS & N & \multicolumn{1}{l}{ \% } \\
\hline Interesse circunstancial & 12 & 44,44 \\
\hline Saturação temática & 7 & 25,93 \\
\hline Preferência por notícias & 4 & 14,81 \\
\hline Monotonia argumentativa & 2 & 7,41 \\
\hline Falta de tempo & 2 & 7,41 \\
\hline Total & 27 & 100 \\
\hline
\end{tabular}

Fonte: Elaboração própria.

O interesse circunstancial é entendido pelos entrevistados como momentâneo, ou seja, não se trata de interesse específico pelo gênero editorial em si, ao contrário do que foi apresentado anteriormente, mas pelos editoriais que tratam de certos temas, dependendo do contexto político e das circunstâncias, conforme exposto abaixo:

\footnotetext{
- Leio quando uma questão diz respeito aos meus interesses;

- Nem sempre os editoriais são convidativos à leitura, o que leva a ler eventualmente, quando se trata de um assunto que estou cobrindo ou simplesmente me desperta interesse e curiosidade;

- Só leio quando é um assunto que tenho muito interesse, para saber como o jornal conduz o debate.
}

Quanto à saturação temática, os entrevistados alegam que os editoriais passaram a explorar muito determinados assuntos políticos, de forma repetida e exaustiva:

- Os editoriais costumam bater na mesma tecla, tratando dos mesmos temas e das mesmas questões políticas, o que torna a leitura cansativa e desinteressante;

- Atualmente me encontro sob uma saturação de notícias e opiniões políticas. Os editoriais sobre corrupção, por exemplo, já estão saturados. Por isso deixei de ler ou leio esporadicamente. 
- Confesso que, cada vez mais, leio menos editoriais sobre política. Isto porque a temática se repete incessantemente em torno da Operação Lava Jato a tal ponto que é difícil acompanhar as nuanças de pontos de vista dos jornais.

Os entrevistados que responderam que leem editoriais às vezes ou raramente porque preferem o noticiário, explicam que "os editoriais estão cada vez mais vazios de argumentos efetivamente relevantes, por isso vou direto nas notícias porque consigo ter uma visão do noticiário, sem o enviesamento argumentativo dos editoriais". Outro informante explica que "preciso ter uma visão abrangente da política e os editoriais se detêm a uma questão ou outra, com uma visão mais restrita e limitada, o que me leva direto para as manchetes".

A monotonia argumentativa se diferencia da saturação temática não visão dos jornalistas que usaram essa justificativa. "Os jornais são pouco criativos quando se trata de opinião. Os argumentos usados são estreitos, repetidos e monótonos, sem criatividade e sem ousadia". Outro entrevistado argumenta que "a monotonia argumentativa chega ao ponto de editoriais de jornais diferentes usarem os mesmos argumentos sobre temas políticos, empobrecendo o espectro da análise e da interpretação da política". Outro informante complementa que "quando se trata de editorial político é uma mesmice só, uma monotonia opinativa". A falta de tempo para a leitura, na realidade significa desinteresse pelos editoriais, embora isso não tenha sido usado explicitamente pelos entrevistados.

O desinteresse dos jornalistas pelos editoriais também pode ser analisado à luz do conceito de razões práticas de Bourdieu (1996). A questão do interesse e do desinteresse dos agentes sociais por determinados assuntos é analisada pelo autor a partir do conceito de illusio, no âmbito de sua sociologia das práticas sociais, na qual se insere a noção de razões práticas. I/lusio, nesse contexto, significa envolvimento no jogo social que legitima ou não determinadas visões práticas dos sujeitos de um mesmo campo social. Assim, quanto maior o interesse, maior o envolvimento dos sujeitos no jogo, o que significa compartilhar os valores, os quais funcionam como suporte simbólico para a ação socialmente legitimada e valorizada por um grupo ou coletividade.

O desinteresse, ao contrário, significa baixo engajamento cognitivo no jogo, o que faz o sujeito se sentir fora do campo e alheio às razões práticas valorizadas no interior desse mesmo campo, isto é o indivíduo está desprovido de illusio. Em suma, os jornalistas que revelam pouco interesse pelos editoriais certamente não estão envolvidos no jogo diário da cobertura política ou fazem seu trabalho sem a necessidade premente de recorrer aos recursos de opinião, análise e interpretação fornecidos pelos editoriais.

\section{Funções dos editoriais}

Os entrevistados destacam como principal função dos editoriais "tentar influenciar a opinião pública" (93,3\%). A segunda alternativa aparece com $43,7 \%$, é a de reforçar a opinião das elites, como mostra a Tabela 5. Em seguida aparecem "reforçar a opinião de grupos de interesse" (33,6\%), "esclarecer o leitor sobre a opinião do jornal" (15,1\%), "alinhar-se aos grupos de interesse" $(15,1 \%)$, "alinhar-se aos interesses dos anunciantes" (15,1\%), "contrapor-se à visão dominante das elites políticas" (1,7\%). 
Tabela 5: Na sua opinião, quais são as principais funções dos editoriais sobre política na atualidade?

\begin{tabular}{l|c|c}
\hline RESPOSTAS & $\mathbf{N}$ & $\mathbf{\%}$ \\
\hline Tentar influenciar a opinião pública & 111 & 93,3 \\
\hline Reforçar a opinião das elites políticas & 52 & 43,7 \\
\hline Reforçar a opinião de grupos de interesse & 40 & 33,6 \\
\hline Esclarecer o leitor sobre a opinião do jornal & 18 & 15,1 \\
\hline Alinhar-se aos interesses dos anunciantes & 18 & 15,1 \\
\hline Contrapor-se à visão dominante das elites políticas & 2 & 1,7 \\
\hline Total & 241 & 100 \\
\hline Fonte: Elaboração própria. &
\end{tabular}

Tentar influenciar a opinião pública, embora seja a função mais relevante na opinião dos entrevistados, apresenta diferentes visões e perspectivas. Uma delas é a de "manipulação da opinião pública", expressão repetida em várias entrevistas, conforme transcrito abaixo:

- Financiados pelas grandes corporações, os principais meios de comunicação funcionam como importantes instrumentos de manipulação da opinião pública. Hoje isso se dá de maneira efetiva por meio dos editoriais.

- Como um desserviço à liberdade de imprensa, um empobrecimento do debate sociopolítico na sociedade e uma tentativa de manipulação da opinião pública a favor do status quo.

- Posicionamento ideológico e tentativa de manipulação de opiniões.

- Há mais uma tentativa de manipulação do que de esclarecimento sobre determinada pauta (grifos acrescentados).

Ao atribuir aos editoriais o poder de "manipular a opinião pública" parece haver um exagero na percepção dos entrevistados, visto que a média de leitores de jornais interessados nesse gênero textual é da ordem de 5\% (Campo, 2009). Além disso, vários entrevistados chamam atenção para a pluralidade de fontes de informação e de opinião na área política, com os blogs e as mídias digitais. Em suma, parece se tratar de uma concepção extremista que não compartilhada pela maioria dos informantes, mas apenas por uma parcela.

Outro segmento expressivo faz alusão ao poder de influência dos editoriais na opinião pública, mas sem mencionar o termo manipulação. Influência aqui parece ser utilizada pelos informantes com outro sentido, como algo distinto de manipulação. Influência seria algo menos categórico e menos enfático do que manipulação e algo mais "naturalizado", isto é, como se fosse inerente às funções da imprensa, desde suas origens, conforme se observa nos trechos transcritos abaixo:

- No mais das vezes, exceto por publicações que se declaram optantes por uma via ideológica/política (como a The Economist, por exemplo), entendo que os 
editoriais buscam criar um clima de consenso na população, enviesado ao interesse do grupo editorial.

- Tentar a influenciar a opinião pública é uma das mais antigas funções dos jornais / meios de comunicação;

- Os editoriais sempre, desde o início de sua existência, tentam influenciar a opinião pública e com a política não seria diferente, ainda mais em tempos turbulentos como os que vivemos no Brasil.

- Acredito que os editoriais, via de regra, buscam influenciar a opinião pública e demonstram qual é o posicionamento daquele meio de comunicação.

A maioria dos entrevistados analisa como negativa a influência dos editoriais na opinião pública, "pois é uma forma tendenciosa de opinar e tentar impor uma visão da política". Outro entrevistado explica que,

"ao opinar e tentar conduzir a opinião pública, o jornal torna-se o porta-voz de certas vertentes do poder, pois, nesses casos, o editorial deixa ser um recurso interpretativo para o leitor e passa a prestar um serviço a alguns grupos políticos, pois torna-se uma opinião alinhada aos interesses de desses grupos".

Um dos respondentes escreveu que "a opinião do jornal nunca é gratuita nem inocente, mesmo quando aparentemente não está a serviço deste ou daquele grupo político". Um dos informantes questionou o hábito da imprensa de "trabalhar no sentido de 'vender' o que é o mais interessante para o momento, seja na forma de notícia ou de opinião, transformando tudo em espetáculo, nem sempre querendo influenciar politicamente o leitor, mas simplesmente em chamar a atenção, na forma de espetáculo".

A visão dos entrevistados remete à célebre discussão sobre manipulação e influência nas teorias da comunicação. Conforme Wolf (1995), a discussão faz parte do repertório conceitual da Communication Reserach, uma das áreas de pesquisa inaugurais sobre os efeitos da comunicação de massa na sociedade, conduzida por sociólogos estadunidenses no período entreguerras. A manipulação foi atribuída como efeito da propaganda política baseada no modelo estímulo-reposta da chamada bullet theory ou teoria hipodérmica. Segundo esse modelo, o efeito esperado da audiência era sempre passível de ser atingido (resposta), desde que o estímulo fosse utilizado de forma adequada. Trata-se de uma perspectiva ancorada em um pressuposto de superpoderes dos mídias de forma unilateral perante uma massa atomizada e psicologicamente vulnerável às mensagens divulgadas.

A influência, por sua vez, resultaria de um processo mais sofisticado, no qual os efeitos esperados, ou seja, a resposta, depende não só do estímulo adequado, mas também do perfil psicológico da audiência e do contexto sociocultural. Nessa outra perspectiva as relações interpessoais são vistas como fatores que poderiam limitar os possíveis efeitos das mensagens midiáticas, a exemplo do poder de influência dos líderes de opinião e do acesso a fontes alternativas de informação e de opinião. Nessa perspectiva, a influência seria um efeito menos totalitário e unilateral da mídia, ao se considerar a interferência de outros fatores de ordem cognitiva, social e cultural. 
As duas visões aparecem nas entrevistas, mas chama atenção o argumento da "manipulação", como se os editoriais tivessem o poder de moldar a opinião do público à moda do antigo modelo estímulo-resposta. Tal perspectiva presente nas entrevistas dos jornalistas desconsidera que os fatores intervenientes na formação de opinião são cada vez mais variados e complexos. As abordagens associadas à noção de influência dos editoriais parecem ser mais adequadas para o atual contexto, pois estão alinhadas com a atual noção de "plasticidade das razões práticas" e de "instancialização das ações" e os intercâmbios entre agência e estrutura. Apesar de essa ideia fazer parte das análises de Bourdieu (1996), talvez seja Giddens (1984) um dos autores de maior expressão nesse campo analítico. Para Giddens, a plasticidade ocorre dos dois lados, ou seja, tanto as estruturas moldam os agentes, como a os agentes mudam as estruturas. Isso significa de que certos editoriais até podem influenciar a opinião do leitor ou reforçar determinadas tendências e visões, mas não "manipular". Além disso, as visões dos leitores também podem influir nos enquadramentos opinativos dos jornais.

\section{Reforço da opinião das elites políticas}

Nesse quesito, um dos entrevistados afirma que "não há dúvida de que os meios de comunicação sempre se alinham aos interesses dos setores que dominam a economia e a política, especialmente quando se trata de questões estruturantes". Outro informante argumenta que "os editoriais sempre se alinham ao grupo que domina a mídia" e complementa que "os interesses políticos e econômicos dos veículos parecem estar acima dos interesses da sociedade". Em um dos relatos, está escrito que "grupos de mídia têm forte interesse na condução da política nacional, especialmente do ponto de vista econômico, pois isso afeta diretamente o mercado de anúncios". Por essa razão, geralmente políticos e empresários "mantém uma relação próxima e usam os meios de comunicação para vender seus produtos e ideias. E em um momento de crise no jornalismo, ganha quem paga mais e quem paga mais geralmente é a elite".

Outra perspectiva presente nas entrevistas é a de que "os editoriais refletem o oportunismo político dos jornais", ou seja, "refletem o que o que jornais querem destacar na agenda política do momento, devido a interesses que nem sempre são visíveis para os leitores". Para outro entrevistado, "a elite funciona como uma mão invisível que conduz a política editorial dos jornais; quando a opinião e os interesses das elites muda, os editoriais também mudam o tom". Ainda sob essa ótica, outro argumento apresentado é que "o jornal atua de forma estratégica, inclusive nos editoriais, que podem reforçar a importância de algumas agendas e apresentar demandas ao campo político".

Alguns dos entrevistados questionam a função original dos editoriais, de provocar o debate público, sem necessariamente "conduzir o leitor a certas conclusões" ou "assumir como sendo do jornal a opinião de um grupo político com influência nas elites responsáveis pelas grandes decisões do país". Para um dos entrevistados,

"ao se posicionar sobre certos temas políticos simplesmente para cumprir acordos de opinião com as elites, o jornal exacerba sua função e sua esfera de atuação, além de trair a confiança de seus leitores, que pensam que a opinião 
expressa no editorial é realmente uma opinião apresentada ao público com a finalidade de contribuir para o debate público democrático".

Em razão disso, complementa outro entrevistado:

"a opinião do jornal - que é legítima e deve ser explicitada aos leitores pelo veículo - muitas vezes apenas se coaduna a grupos de interesse econômico ou político, como os grandes anunciantes, sem que haja uma análise realista dos fatos, que poderia contribuir efetivamente para a democracia. Ao se alinhar as elites e servir de porta-voz de grupelhos de interesses duvidosos, os jornais atuam contra a democracia e contra o leitor."

Por outro lado, há entrevistados que ressaltam que

"se um jornal é um agente político, logo é ingênuo idealizar suas funções, imaginar que deveria agir de forma democrática e coisa e tal. Como um agente inserido no jogo de poder, jamais um jornal será neutro, plural ou defensor de interesses de maiorias sem nenhum poder. Sendo uma peça do sistema de poderes, qualquer jornal vai atuar de forma estratégica para tirar proveito do poder, usando todas as suas ferramentas, inclusive os editoriais. Não podemos ser ingênuos, inocentes e idealistas".

Quanto à relação dos jornais com os grupos de interesses, a avaliação dos entrevistados é que se diferencia em parte da relação com as elites no sentido amplo, pois "há grupos de interesse que são da elite e outros que não são". Um dos entrevistados resumiu que "a relação dos jornais com a elite é uma relação estável e duradoura, enquanto a relação com os grupos de interesse - na maioria dos casos - é eventual e momentânea". Isso significa que "há situações em que os jornais se alinham a certos grupos de interesse como estratégia de reforço e do alcance de suas opiniões, mas resolvido o problema do momento, aquele grupo de interesse não consegue mais interferir na opinião do jornal". Em resumo, é como se os grupos de interesses fossem responsáveis por causas episódicas que conseguem o apoio momentâneo dos jornais, mas apenas naquele momento em que "houve convergência entre os dois lados, mas uma convergência passageira, sem necessariamente haver duração ou continuidade", como explica um dos entrevistados. Os que acham que a função do editorial é esclarecer o leitor sobre a opinião do jornal $(15,1 \%)$, justificam tal viés pela perspectiva das relações de consumo. "Já que o jornal é uma empresa que informação e opinião, o leitor tem o direito de saber a posição do jornal sobre os temas políticos". Os entrevistados que pensam que a função do editorial é "alinhar-se aos grupos de interesse" (15,1\%), acham tal postura "legítima, pois não existe atividade comercial sem interesse". Aqueles que responderam que a função do editorial é "alinharse aos interesses dos anunciantes" (15,1\%), também tratam o jornal como um negócio, em que "opinião e informação servem de suporte para anúncios". Os dois entrevistados que concordam que a função do editorial é "contrapor-se à visão dominante das elites políticas" pensam que "o contraponto é parte da 
democracia e os jornais não são necessariamente aparelhos ideológicos das elites e há momentos em que os jornais atuam como agentes firmes no questionamento dos valores políticos da nossa elite retrógrada". O que se observa na análise dos entrevistados em relação a esse tópico é uma variedade de perspectivas, o que é interessante em termos de contrapontos, conforme foi exposto acima. Entretanto, apesar disso, há muitos depoimentos que se alinham à perspectiva estereotipada da "mídia má", um tema recorrente na literatura sobre sociologia da mídia, a exemplo dos estudos de Lemieux (2000; 2010). Com base em estudos etnográficos o autor contesta a tese da "construção da realidade" pelos mídias. Seu principal argumento é o de a mídia não atua isoladamente, mas em cooperação e competição com vários outros atores, como os próprios políticos e os públicos. Nessa perspectiva, um editorial seria uma produção coletiva. A opinião de um jornal não seria, portanto, algo tão exclusivo daquele veículo específico, mas resultante de um conjunto de forças e de um jogo com vários atores envolvidos. Dessa forma, tanto uma notícia como um texto opinativo seriam modos que os jornalistas usam para traduzir e expressar ideias coletivas, embora nem sempre consensuais.

Todos os entrevistados concordam que os editoriais exercem influência no debate público atualmente. A opção "não exercem nenhuma influência" não registrou nenhuma adesão, como mostra a Tabela 6.0 que varia é a escala e o grau de influência, na visão dos informantes. Nessa escala, 40,8\% responderam que os editoriais exercem influência cada vez menor; $37,7 \%$ que exercem influência moderada; $10 \%$ que exercem grande influência; $7,5 \%$ que exercem influência muito reduzida; e 4,2\% que depende do tema e do contexto.

Tabela 6: Como você avalia a influência dos editoriais no debate político na atualidade?

\begin{tabular}{l|c|c}
\hline RESPOSTAS & $\mathbf{N}$ & $\mathbf{\%}$ \\
\hline Exercem influência cada vez menor & 50 & 40,8 \\
\hline Exercem influência moderada & 44 & 37,7 \\
\hline Exercem grande influência & 12 & 10 \\
\hline Exercem influência muito reduzida & 9 & 7,5 \\
\hline Depende do tema e do contexto & 5 & 4,2 \\
\hline Não exercem influência nenhuma & 0 & 0 \\
\hline Total & 120 & 100 \\
\hline
\end{tabular}

Fonte: Elaboração própria.

Entre aqueles que acham que os editoriais exercem influência moderada ou cada vez menor destacam-se justificativas relacionadas à diversificação do campo midiático:

- Já exerceram grande influência, mas atualmente não, pois os meios de informação e opinião se diversificaram muito com a internet.

- As redes sociais e os blogs deram voz a uma infinidade de opiniões, reduzindo a influência dos editoriais. 
- Há hoje uma pluralidade de fontes de opinião. Os jornais são importantes, mas já têm espaço reduzido devido à concorrência com tantas outras fontes.

- Existem vários outros fatores importantes que influenciam a opinião pública redes sociais, hoje, são mais fortes que editoriais.

Um dos entrevistados mencionou que "já se foi o tempo em que editorias da imprensa agitavam a esfera pública". Atualmente, "são meras peças discursivas que repercutem quase que exclusivamente dentre as próprias elites para as quais são redigidas; quando muito, ecoam no Congresso Nacional por meio de parlamentares interessados tanto no eventual tema em questão quanto em bajular o veículo de comunicação". Outro argumento é o de que "os editoriais sempre terão o seu lugar e sua relevância política". Mesmo reduzindo o número de leitores, "trata-se de um produto que tem uma 'aura' já consagrada, um certo ar de prestígio, de status, algo quase mítico. Falou em editorial contra ou a favor de certo tema, vai gerar interesse e discussão, mesmo que seja só entre os próprios jornalistas ou na esfera política". Isso porque, segundo outro entrevistado, "o editorial nunca foi concebido para ser um produto de massa, mas para uma parcela reduzida de leitores, porém um segmento influente, seja a elite política, a nata do setor econômico ou mesmo outro tipo de elite".

Outros entrevistados objetam que,

\begin{abstract}
"os editoriais sozinhos talvez não exerçam tanta influência, mas certamente o recorte deles aparece na configuração geral do jornal, o que acaba tendo maior influência. Uma reflexão sobre editorias não deve focar apenas no editorial de forma isolada, mas nas conexões dele com o conjunto do noticiário, especialmente com a arquitetura noticiosa que resulta na escolha das manchetes de primeira página, nas fotos, no destaque a algumas declarações de autoridades, entre outros fatores. É esse conjunto que exerce influência persuasiva e não apenas o editorial isoladamente".
\end{abstract}

Aqueles entrevistados que acreditam que os editoriais ainda exercem grande influência, justificam que "continuam sendo relevantes para o debate público e lidos pela classe política". Outros informantes alegam que "a influência não está associada necessariamente a uma grande quantidade de leitores, mas principalmente ao valor simbólico que o gênero editorial conquistou ao longo da história do jornalismo". Nessa mesma linha de raciocínio outro informante considera que "estamos tratando de influência política, algo muito específico, que não se aplica obrigatoriamente a grande contingente de leitores, mas a alguns segmentos, aqueles eleitores capazes de exercer influência na política e não o leitor comum, que está fora e distante das esferas decisórias". Em resumo, há praticamente um consenso entre os entrevistados desse segmento de que os editoriais permanecem como uma forma expressiva de opinião política, consideradas as especificidades do atual contexto midiático.

Por fim estão aqueles que acreditam que os editoriais podem ser relevantes ou não em função do tema e do contexto. "Acho muito difícil tratar o assunto de forma categórica, pois acredito que não é possível generalizar e considerar o editorial como uma entidade abstrata, descolada da realidade". Outro informante 
complementa que "depende do jornal, do assunto que está sendo tratado, do momento, se há polêmica ou comoção envolvida, do número de pessoas afetadas, entre outros fatores". Um dos entrevistados explica que "não há uma regra geral, pois há editoriais de grande impacto no debate público e outros sem grande relevância, o que nos leva a pensar em diferentes escalas e níveis de influência dos editoriais e dos próprios veículos de mídia".

Da mesma forma que no item anterior, observamos uma variedade de abordagens na opinião dos entrevistados, mas a partir de uma perspectiva comum, centrada na manutenção ou na alteração das dinâmicas de poder do próprio jornalismo, como a emergência das mídias digitais e o contexto cultural relacionado ao novo ambiente tecnológico. Pouco se falou, contudo, sobre as reconfigurações do debate público em si e das redefinições relativas aos novos modelos de esfera pública. Embora isso não tenha sido perguntado diretamente, o pressuposto era o de que tais questões permeariam o debate, especialmente em função do perfil do público entrevistado, visto que os jornalistas são agentes por excelência do debate que ocorre na esfera pública.

A própria noção de jornalismo opinativo e de editorial, especificamente, está diretamente associada a essa discussão, conforme foi demonstrado na primeira parte do texto. O silêncio dos entrevistados quanto a isso talvez seja explicado pela própria noção de esvaziamento de debate público na atualidade, conforme registra Bauman (2010; 2015). O autor faz referência a uma aguda crise nos debates públicos na atualidade, com o "desaparecimento ou redução das arenas voltadas para a deliberação pública e política" (2015, p.120), em "um mundo saturado de opiniões que se opõem e que mutuamente corroem sua veracidade real ou suposta" (BAUMAN, 2015, p.105). O jornalismo opinativo e os editoriais, especificamente, parecem fazer parte desse cenário de crise discursiva apontada pelo autor, o que se deduz do silêncio dos entrevistados quanto a esse aspecto.

\section{Conclusões}

A análise das entrevistas apresenta resultados inusitados, como a crença dos informantes no poder de "manipulação" dos editoriais, com reflexos diretos na formação da opinião pública e no reforço da opinião das elites políticas. Paradoxalmente, outra parte dos respondentes defende a ideia de que o editorial reduziu sua capacidade de influir no debate político, embora ainda seja um dispositivo capaz de exercer alguma influência, a depender do tema, do capital editorial do veículo e do contexto. Nesse sentido, acreditamos que o estudo apresenta uma contribuição significativa para o entendimento da relação entre jornalismo opinativo e debate político, a partir da perspectiva do editorial, um gênero muito valorizado no passado, mas que foi praticamente esquecido nos últimos anos, inclusive como objeto de estudo.

Apesar de apresentar questões específicas, o estudo aqui exposto permite relacionar tais questões específicas com um cenário reflexivo mais abrangente, como a relação entre imprensa e esfera pública, uma das bases dos estudos históricos e teóricos sobre o assunto, como foi registrado na primeira parte do estudo, especialmente com as contribuições de Habermas sobre a relevância da opinião da esfera pública burguesa. Apesar disso, existem estudos mais recentes que apontam uma progressiva perda da importância dos editoriais como instrumento fomentador do debate público (DEMERS, 2016). É oportuno salientar que as 
entrevistas também apontaram esse argumento, havendo, portanto, convergência entre os estudos acadêmicos e a perspectiva dos entrevistados quanto à progressiva perda do poder de influência dos editoriais no debate político atualmente.

Tal perspectiva põe questões para aprofundar o debate entre imprensa e democracia no atual cenário midiático e político, uma das perspectivas mais presentes nos estudos sobre mídia e política. Na esteira de tal problemática está a análise da própria relação entre o editorial e as reconfigurações do jornalismo político, especialmente no que diz respeito a seu papel de arena discursiva na modernidade. Uma perspectiva interessante apontada pelos entrevistados refere-se a uma provável "migração" do caráter opinativo e interpretativo do editorial para o campo informativo, com a emergência de formatos noticiosos que incorporam visões editorializadas. Tal reconfiguração do jornalismo político teria mais poder de persuasão e de influência na esfera pública e nos debates políticos do que o editorial isoladamente.

Chama atenção na análise das entrevistas o repertório linguístico dos informantes acerca de algumas questões, como a noções de manipulação e de influência. Aliás, cabe o registro de que não apareceu o termo persuasão em nenhum dos depoimentos. Cabe ressaltar a que a ideia de manipulação faz parte de um escopo teórico considerado ultrapassado nas teorias da comunicação, conforme já foi apontado anteriormente. A ideia de influência é acionada de modo mais apropriado às análises mais contemporâneas sobre os prováveis efeitos sociais da atuação da mídia. Influência, como vimos, seria um efeito menos absoluto e mais relativo, condicionado por múltiplos fatores. Trata-se de uma concepção mais condizente com as trilhas analíticas que consideram que o jornalismo é uma atividade complexa e condicionada multifatorialmente.

O uso do termo elites pelos entrevistados é outro ponto que merece maior atenção. Além de não haver consenso, parece ser resultado de uma visão bastante estereotipada e conservadora do termo, como se as elites fossem estamentos separados e dissociados dos demais segmentos da sociedade. $\mathrm{O}$ que se depreende de grande parte das entrevistas é que a noção de elite se limita aos grupos que detém poder político e econômico, sem considerar, por exemplo, as elites culturais. Além disso, os informantes pensam em elites apenas no nível macro, como instâncias muito poderosas, sem considerar a possibilidade de elites intermediárias e também de elites que atuam e exercem poder em escalas hierárquicas menores. 0 mesmo se aplica ao uso da noção de opinião pública, que aparece nos relatos como algo abstrato e generalizável, como se fosse um bloco homogêneo de pensamento.

Por fim, inferimos que a pesquisa revela alguns aspectos relevantes sobre ethos jornalístico, com características expressivas da cultura profissional dessa categoria tão importante para a democracia. As razões práticas, como vimos anteriormente, orientam o ethos desses profissionais, com reflexos diretos na opinião deles acerca dos editoriais, da política e do debate público. Expressões desse ethos podem ser relacionadas com as motivações para ler ou não ler editoriais, para avaliar suas funções e seu maior ou menor potencial de influência nos debates políticos, como vimos anteriormente. 0 estudo tem ainda 0 potencial de apontar para outras possibilidades analíticas sobre a função dos editoriais na atualidade, a partir da análise das perspectivas de outros grupos, como os próprios políticos, os intelectuais e os leitores. 


\section{Referências bibliográficas}

Amaral, L. (1997). Jornalismo: matéria de primeira página. Rio de Janeiro: Tempo Brasileiro.

Azevedo, F. A.; Chaia, V. L. M. (2008). O Senado nos editoriais dos jornais paulistas (2003-2004). Opinião Pública, v. 14, n. 1, p. 173-204.

Báccaro, L.; Nascimento, E. L. (2007). O gênero editorial na perspectiva do interacionismo sóciodiscursivo: o contexto de produção. Anais do V Encontro Científico do Curso de Letras, Londrina, 2007. Disponível em http://www.faccar.com.br/eventos/desletras/hist/2007 g/textos/15.htm Acesso em 27/02/17.

Bardin, L. (2010). Análise de Conteúdo. Lisboa: Edições 70.

Barros, A. T. (1993). A ética de mercado na produção noticiosa do jornal Folha de S. Paulo. Perspectivas, v. 16, n. 1, p. 265-294.

Barros, A. T. (2013). Editoriais jornalísticos sobre ecologia: opinião privada como opinião publicamente mediada. Comunicação \& Informação, v. 3, n. 1, p. 65-79, 2013.

Barros, A. T. (2015). Sociologia da mídia: principais perspectivas e contrapontos. Século XXI - Revista de Ciências Sociais, v. 5, p. 186-222, 2015.

Beltrão, L. (1980). Jornalismo opinativo, Porto Alegre, Sulina, 1980.

Bourdieu, P. (1996). Razões práticas: sobre a teoria da ação. Papirus Editora, 1996.

Brito, S. de. (1994). A argumentação e a perlocução no discurso jornalístico: o editorial. Dissertação de Mestrado (Poéticas Visuais). Universidade Estadual Paulista Júlio de Mesquita Filho.

Campo, P. C. (2001). Gênero Opinativo. Observatório de Imprensa Online. http://www.observatoriodaimprensa.com.br/artigos/da010520026.htm Acesso em 27/92/17

Campo, P. C. (2009). Gêneros do Jornalismo e técnicas de entrevista. Estudos em Jornalismo e Mídia, v. 6, no. 1, p. 127-141.

Cantril, H.; Allport, G. W. (1933). Recent applications of the Study of Values. The Journal of Abnormal and Social Psychology, v.28, no. 3, p. 259-267.

Cavalcanti, Maria Emília Tavares Varela; ROCHA NETO, Manoel Pereira (2014). O uso das redes sociais na prática do jornalismo colaborativo. Quipus, v. 3, n. 2, p. 65-78.

Chaparro, M. C. (1994). Pragmática do jornalismo: buscas práticas para uma teoria da ação jornalística. São Paulo: Summus.

Chauí, M. (1986). Imprensa e democracia. Folha de S. Paulo, 30/06/86, p.3.

Cook, T. (1998). Governing with the News - The News Medias as a Political Instittion. The University of Chicago Press.

Demers, F. (2016). O editorial e o debate público. Sobre jornalismo, v. 5, n. 2, p. 88-91, 2016.

Dowling, D. (2016). The Emergence of the Progressive Editorial in the Nineteenth-Century Press. Sobre jornalismo, v. 5, n², p. 106-119.

Erbolato, M. L. (2002). Técnicas de codificação em jornalismo: redação, captação e edição no jornal diário. São Paulo: Ática.

Faria, M. A. (1996). O jornal na sala de aula. São Paulo: Contexto, 1996. 
Firmstone, J., (2008). The editorial production process and editorial values as influences on the opinions of the British press towards Europe. Journalism Practice, v. 2, n.2, 2016, p. 212-229.

Krieger, M. da G. (1990). Editoriais jornalísticos: discursos de representação do interesse coletivo. Revista de Biblioteconomia e Comunicação. Porto Alegre, n.5, p.158-164, dez. 19

Guerreiro Neto, G. (2016). Da opinião à identidade. Características do editorial em dois jornais brasileiros. Sobre jornalismo, v. 5, n², p. p.92-105.

Giddens, A. (1989). A constituição da sociedade. São Paulo: Martins Fontes, 1989.

Habermas, J. (1984). Mudança estrutural na esfera pública. Rio de Janeiro: Tempo Brasileiro.

Lefèvre, F.; Lefèvre, A. M. C. (2003). O discurso do sujeito coletivo: um novo enfoque em pesquisa qualitativa; desdobramentos. Educs, 2003.

Lemos, C. R. F.; Barros, A. T. (2016). Lutas simbólicas na arena midiática: o poder de agência do Ministério Público e as controvérsias sobre a PEC 37. Opinião Pública, Campinas, v.22,n. 3,p. 702738.

Lemieux, C. (2000). Mauvaise presse: une sociologie compréhensive du travail journalistique et de ses critiques. Paris: Métailié.

Lemieux, C. (2010). La subjectivité journalistique: Onze leçons sur le rôle de l'individualité dans la production de l'information. Paris: Editions Ehess, 2010.

Manfreda, Katija, Losar; Vehovar, Vasja (2008). Internet Survey. In: LEEUW, Edith Desirée; Hox, J. J.; Dillman, Don A. (Eds). International handbook of survey methodology. London: Taylor \& Francis, p.264-283.

Melo, J. M. (1985). A opinião no jornalismo brasileiro, Petrópolis, Vozes.

Miguel, L. F.; Coutinho, A. de A. (2007). A crise e suas fronteiras: oito meses de "mensalão" nos editoriais dos jornais. Opinião Pública, v. 13, n. 1, p. 97-123.

Mont'Alverne, C.; Marques, J. (2013). Jornalismo político e imagem pública: Dilma Rousseff nos editoriais do jornal O Estado de S. Paulo. Contracampo, v. 28, n. 3, p. 92-11.

Park, R. E. (2008). Notícia e o poder da imprensa. In: Berger, C., Marocco, B. (Org.). A era glacial do jornalismo: teorias sociais da imprensa, vol. 2, Porto Alegre, Sulina, p. 71-82.

Pichelli, K. R.; Pedro, M.; Carvalho, M. de A. (2007). O discurso de formação da opinião pública: análise dos editoriais sobre as denúncias do "Mensalão" nas revistas Veja e Carta Capital. UNI Revista. São Paulo, v. 1, no. 3.

Pires, R. P.; (2015). Modos de explicação. Sociologia, Problemas e Práticas, s.v., n. 78, p. 125-141.

Quivy, Raymond e Campenhoudt, Luc Van (2005). Manual de Investigação em Ciências Sociais, 4a Ed., Gradiva, Lisboa

Ribeiro, L. M. (2004). Imprensa e espaço público: a institucionalização do jornalismo no Brasil, 1808-1964. São Paulo: Editora E-papers.

Silva, C. L. (2009). A Carta ao Leitor de Veja: um estudo histórico sobre editoriais. Intercom-Revista Brasileira de Ciências da Comunicação v.32, no. 1, p.89-102.

Thompson, J. B. (1995). Ideologia e cultura moderna: teoria social crítica na era dos meios de comunicação. Petrópolis: Vozes. 
Vallim, J. R.; Schoenherr, R. (2011). Opinião nos Jornais: uma discussão sobre o jornalismo opinativo atual como construção histórica. Anais do XII Congresso de Ciências da Comunicação na Região Sul, Londrina - PR, 26 a 28 de maio de 2011.

Wahl-Jorgensen, K. (2008). "Op-ed pages". In: Franklin, B. (Ed.), Pulling newspapers apart. analysing print journalism. London, Routledge, p. 67-74.

Weber, M. (1999). Economia e Sociedade. Brasília: EdUnB.

Weber, M. 2005 [1910]. Sociologia da Imprensa: um programa de pesquisa. Estudos em Jornalismo e Mídia, 2, no. 1 , p. 13-21.

Wolf, M. (1995). Teorias da comunicação. São Paulo: Martins Fontes. 